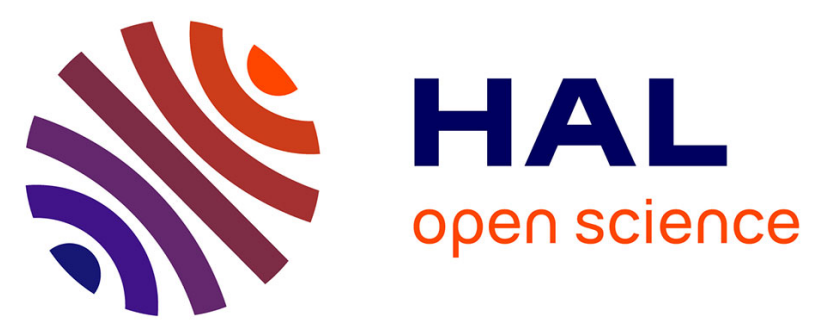

\title{
Variations in modeled atmospheric transport of carbon dioxide and the consequences for $\mathrm{CO} 2$ inversions
}

\author{
R. Law, P. Rayner, A. Denning, D. Erickson, I. Fung, M. Heimann, S. Piper,
} M. Ramonet, S. Taguchi, J.A. Taylor, et al.

\section{- To cite this version:}

R. Law, P. Rayner, A. Denning, D. Erickson, I. Fung, et al.. Variations in modeled atmospheric transport of carbon dioxide and the consequences for CO 2 inversions. Global Biogeochemical Cycles, 1996, 10 (4), pp.783-796. 10.1029/96GB01892 . hal-03115975

\section{HAL Id: hal-03115975 \\ https://hal.science/hal-03115975}

Submitted on 6 Feb 2021

HAL is a multi-disciplinary open access archive for the deposit and dissemination of scientific research documents, whether they are published or not. The documents may come from teaching and research institutions in France or abroad, or from public or private research centers.
L'archive ouverte pluridisciplinaire HAL, est destinée au dépôt et à la diffusion de documents scientifiques de niveau recherche, publiés ou non, émanant des établissements d'enseignement et de recherche français ou étrangers, des laboratoires publics ou privés. 


\title{
Variations in modeled atmospheric transport of carbon dioxide and the consequences for $\mathrm{CO}_{2}$ inversions
}

\author{
R. M. Law, ${ }^{1}$ P. J. Rayner, ${ }^{1}$ A. S. Denning, ${ }^{2}$ D. Erickson, ${ }^{3}$ I. Y. Fung, ${ }^{4}$ \\ M. Heimann, ${ }^{5}$ S. C. Piper, ${ }^{6}$ M. Ramonet, ${ }^{7}$ S. Taguchi, ${ }^{8}$ J. A. Taylor, ${ }^{9}$ \\ C. M. Trudinger, ${ }^{10}$ and I. G. Watterson ${ }^{10}$
}

\begin{abstract}
Carbon dioxide concentrations due to fossil fuel burning and $\mathrm{CO}_{2}$ exchange with the terrestrial biosphere have been modeled with 12 different three-dimensional atmospheric transport models. The models include both on-line and off-line types and use a variety of advection algorithms and subgrid scale parameterizations. A range of model resolutions is also represented. The modeled distributions show a large range of responses. For the experiment using the fossil fuel source, the annual mean meridional gradient at the surface varies by a factor of 2 . This suggests a factor of 2 variation in the efficiency of surface interhemispheric exchange as much due to differences in model vertical transport as to horizontal differences. In the upper troposphere, zonal mean gradients within the northern hemisphere vary in sign. In the terrestrial biotic source experiment, the spatial distribution of the amplitude and the phase of the seasonal cycle of surface $\mathrm{CO}_{2}$ concentration vary little between models. However, the magnitude of the amplitudes varies similarly to the fossil case. Differences between modeled and observed seasonal cycles in the northern extratropics suggest that the terrestrial biotic source is overestimated in late spring and underestimated in winter. The annual mean response to the seasonal source also shows large differences in magnitude. The uncertainty in hemispheric carbon budgets implied by the differences in interhemispheric exchange times is comparable to those quoted by the Intergovernmental Panel on Climate Change for fossil fuel and ocean uptake and smaller than those for terrestrial fluxes. We outline approaches which may reduce this component in $\mathrm{CO}_{2}$ budget uncertainties.
\end{abstract}

\section{Introduction}

This paper presents a summary of some of the major results from the $\mathrm{CO}_{2}$ Transport Comparison Project

\footnotetext{
${ }^{1}$ Cooperative Research Centre for Southern Hemisphere Meteorology, Monash University, Clayton, Victoria, Australia.

${ }^{2}$ Department of Atmospheric Science, Colorado State University, Fort Collins.

${ }^{3}$ National Center for Atmospheric Research, Boulder, Colorado.

${ }^{4}$ Centre for Earth and Ocean Research, University of Victoria, Victoria, British Columbia, Canada.

${ }^{5}$ Max Planck Institut für Meteorologie, Hamburg, Germany.

${ }^{6}$ Scripps Institution of Oceanography, La Jolla, California.

${ }^{7}$ Centre des Faibles Radioactivites, Laboratoire Mixte, CNRS/CEA, Gif-sur-Yvette, France.

${ }^{8}$ National Institute for Resources and Environment, Tsukuba, Ibaraki, Japan.

${ }^{9}$ Centre for Resource and Environmental Studies, Australian National University, Canberra, Australian Capital Territory, Australia.

${ }^{10}$ Division of Atmospheric Research, CSIRO, Aspendale, Victoria, Australia.

Copyright 1996 by the American Geophysical Union.

Paper number 96GB01892.

$0886-6236 / 96 / 96 \mathrm{~GB}-01892 \$ 12.00$
}

(TransCom). The project was initiated at the 4th International $\mathrm{CO}_{2}$ Conference at Carqueiranne, France, in 1993. Its initial aim was to provide a qualitative understanding of the importance of differences in atmospheric tracer transport models used in $\mathrm{CO}_{2}$ budget studies. The need for the project arose from the considerable variation in global budgets arising from such studies as Keeling et al. [1989], Taylor [1989], Tans et al. [1990], and Enting et al. [1995]. The uncertainties represented by the range of proposed budgets propagate into the future as uncertainties in the evolution of $\mathrm{CO}_{2}$ concentration [Enting et al., 1994].

To understand how differences in transport characteristics of atmospheric tracer models appear as differences in $\mathrm{CO}_{2}$ budgets, it is necessary to review how such models are used. The input data is a record of atmospheric trace gas concentrations (mainly $\mathrm{CO}_{2}$ ) at a range of sites around the world. The record commences with the measurements of C. D. Keeling in the late 1950s at the south pole and Mauna Loa [Keeling et al., 1995]. Spatial coverage increased gradually through the 1960s and 1970s, then more rapidly through the 1980s and early 1990s. The spatial distribution of concentration contains information about the spatial structure of sources and sinks of $\mathrm{CO}_{2}$ which is accessed using a model of tracer transport. Atmospheric transport determines the rela- 
tionship between the space-time structure of net sources and the space-time structure of concentration.

In the language of inverse theory, the current concentrations are related to past sources by a linear operator representing transport. "Concentrations" may include multiple species as in the work of Enting et al. [1995]. The problem of estimating $\mathrm{CO}_{2}$ sources, then, is one of inverting the linear operator representing transport. Such an estimate should yield not only an expectation for the source but also an error estimate, for example, in the work of Enting et al. [1993, 1995] and Ciais et al. [1995]. These authors considered the impact on uncertainties in source components due to uncertainties in the input data. They did not consider the impact of errors in the transport operator. As yet, there is no computationally feasible way of characterizing errors in threedimensional atmospheric tracer transport models nor data with which these errors can be established. In the absence of such data, model intercomparison provides one estimate of the uncertainty. In addition, the emergence of consensus on any aspect of transport should reinforce our confidence in results which depend on it.

While it is difficult to characterize model error, there are methods by which models can be validated. Various trace gases can be used to calibrate modeled transport, typical choices being krypton 85, CFCs, and radon [e.g., Prather et al., 1987; Jacob et al., 1987; Heimann and Keeling, 1989; Jacob and Prather, 1990]. However, the limited data available and uncertainties in the sources means that no calibration is comprehensive. It is hoped that a combination of consensus and calibration could reduce the uncertainties in source estimation due to model error.

To provide a quantitative measure of differences in model transport, 12 atmospheric tracer transport models have been run with prescribed sources. The models either have been or are likely to be used in $\mathrm{CO}_{2}$ source studies, and the chosen sources are relevant to the seasonal and annual mean spatial distribution of $\mathrm{CO}_{2}$. This is by no means a complete characterization of model differences, let alone model error, but it is a first step in this direction. It should also aid in interpreting any inversion studies by particular mociels.

\section{Method}

\section{Sources}

Two sources of $\mathrm{CO}_{2}$ were chosen for this comparison. The first was the emissions of $\mathrm{CO}_{2}$ due to fossil fuel burning and cement production. This is one of the best known components of the $\mathrm{CO}_{2}$ budget and makes a good test of a model's interhemispheric transport, since $95 \%$ of the fossil fuel emissions occur in the northern hemisphere. The source data used were provided by I. Fung (personal communication, November 1993) and have been previously used by Tans et al. [1990]. They are based on country estimates derived by Marland [1989] which have been distributed within countries according to population density by I. Fung (personal communication, November 1993). They include no temporal variation. The data were provided on a $1^{\circ}$ grid (Figure 1) with modelers aggregating this to their own model resolution. The difference in resolution among the models introduces small-scale differences into the input sources; for example, the maximum source strength for a grid point in the high resolution Geophysical Fluid Dynamics Laboratory (GFDL) model is $912 \mathrm{~g} \mathrm{C} \mathrm{m}^{-2} \mathrm{yr}^{-1}$ compared to only $515 \mathrm{~g}$ $\mathrm{C} \mathrm{m}^{-2} \mathrm{yr}^{-1}$ in the lower resolution Goddard Institute for Space Studies (GISS) model.

The second source used was the exchange of $\mathrm{CO}_{2}$ with the biosphere. The data were compiled by Fung et al. [1987], combining satellite estimates of photosynthesis with local measurements of respiration and net primary productivity. The sources were validated by comparing modeled (using the GISS model) and observed seasonal cycles of $\mathrm{CO}_{2}$ concentration. This source is the major contributor to the observed seasonal cycle of $\mathrm{CO}_{2}$, at least in the northern extratropics. Thus some comparisons can be made between modeled and observed seasonal cycles. There is also considerable interest in the annual mean $\mathrm{CO}_{2}$ field which results from the combination of seasonal sources and seasonal variation in transport. One recent study, Denning et al. [1995], has demonstrated strong correlations between a modeled planetary boundary layer and sources of $\mathrm{CO}_{2}$, leading to substantial annual mean meridional gradients.

The time-latitude distribution of the vegetation source is shown in Figure 2. The largest seasonality occurs in the northern middle and high latitudes. There are two periods when respiration dominates, indicated by large positive fluxes (May and October). This is balanced by a larger and shorter-lived negative spike during the peak growing season of summer. At other latitudes, the fluxes are smaller and more sinusoidal in nature.

It was recommended that the experiments, referred to here as the fossil and biosphere experiments, be run for at least 3 years from an initial atmosphere with uniform $\mathrm{CO}_{2}$. This provides sufficient time for the model atmosphere to lose any memory of the initial condition. Most modelers provided the fourth year of their simulations for analysis.

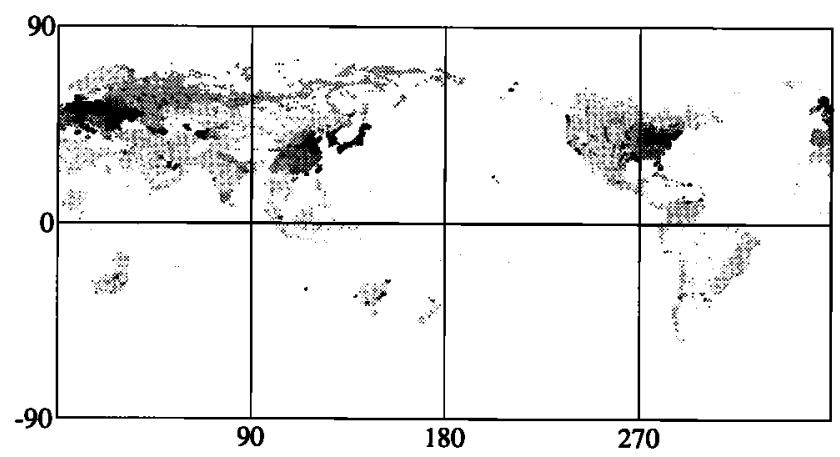

Figure 1. Fossil emissions in $\mathrm{g} \mathrm{C} \mathrm{m}^{-2} \mathrm{yr}^{-1}$. Each $1^{\circ} \mathrm{x}$ $1^{\circ}$ square with nonzero source is shaded. The darker greys indicate higher emissions. The values used to determine the grey shade are $1,50,100,200,500,1000$, and $5000 \mathrm{~g} \mathrm{C} \mathrm{m}^{-2}$ $\mathrm{yr}^{-1}$. 
Table 1a. Model Identification

\begin{tabular}{lll}
\hline \multicolumn{1}{c}{ Model } & \multicolumn{1}{c}{ Modeler } & \multicolumn{1}{c}{ Reference } \\
\hline ANU & J. Taylor & Taylor [1989] \\
CSIRO9 & I. Watterson & Watterson et al. [1995] \\
CSU & A. S. Denning & Denning et al. [1995] \\
GFDL & P. Rayner & Mahlman and Moxim [1978] \\
GISS & C. Trudinger & Fung et al. [1987] \\
MUGCM & R. Law & Law [1993] \\
MUTM & R. Law & Law et al. [1992] \\
NCAR & D. Erickson & Erickson et al. $[1996]$ \\
NIRE & S. Taguchi & Taguchi [1996] \\
TM1 & S. Piper & Heimann and Keeling [1989] \\
TM2 & M. Heimann & Heimann [1995] \\
TM2Z & M. Ramonet & Ramonet et al. [1996] \\
\hline & &
\end{tabular}

\section{Models}

The experiments were run with 12 different tracer transport models. An identifier is allocated to each model in Table 1a and the major characteristics of each model are summarized in Table 1b. The models included full general circulation models (GCMs) which transport trace gases along with other meteorological variables (so-called on-line models) and off-line models, in which the tracer transport is effected by preexisting wind fields. These wind fields can be either model generated or from observed analyses and are applied to the off-line models at various frequencies. The models encompassed a range of horizontal and vertical resolutions and a range of advection schemes. Some models

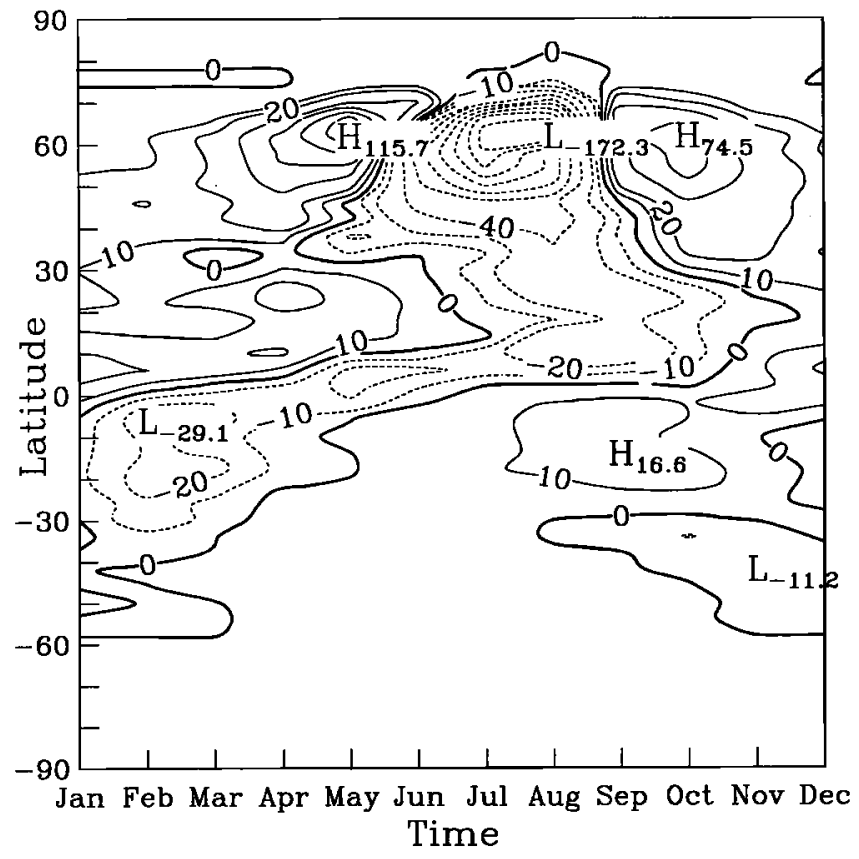

Figure 2. Zonal monthly mean biosphere source. The contour interval is $20 \mathrm{~g} \mathrm{C} \mathrm{m}^{-2} \mathrm{yr}^{-1}$, and the -10 and 10 contours are also shown.

resolve the diurnal cycle. Each model also includes parameterizations of subgrid scale tracer mixing. It is important to note that while different subgrid scale processes are characterized in Table $1 \mathrm{~b}$, in practice, the differentiation is not that simple; for example, seasonal variations in the planetary boundary layer (PBL) may be represented by seasonal

Table 1b. Model Details

\begin{tabular}{|c|c|c|c|c|c|c|c|c|c|c|}
\hline Model & Type $^{a}$ & HRes $^{b}$ & VRes $^{b}$ & $A d v^{c}$ & Wind $^{d}$ & Freq $^{e}$ & Hdif $^{f}$ & Vdiff & $\operatorname{Con}^{f}$ & PBL $^{\mathrm{f}}$ \\
\hline ANU & Off & $2.5^{\circ}$ & 7 & Lag & $\mathrm{EC}(80)$ & Stats & $\mathbf{Y}$ & $\mathbf{Y}$ & $\ldots$ & $\cdots$ \\
\hline CSIRO9 & On & $3.3 \times 5.6^{\circ}$ & 9 & S-L & $\ldots$ & $\ldots$ & $\cdots$ & $\mathbf{Y}$ & $\mathbf{Y}$ & $\cdots$ \\
\hline CSU & On & $4 \times 5^{\circ}$ & 17 & 2nd ord & $\ldots$ & $\ldots$ & $\ldots$ & $\mathbf{Y}$ & $\mathbf{Y}$ & $\mathbf{Y}$ \\
\hline GFDL & Off & 265 km & 11 & 2,4 ord & GFDL & $6 \mathrm{hr}$ & $\mathbf{Y}$ & $\mathbf{Y}$ & $\ldots$ & $\ldots$ \\
\hline GISS & Off & $7.8 \times 10^{\circ}$ & 9 & slopes & GISS & $4 \mathrm{hr}$ & $\mathbf{Y}$ & $\ldots$ & $\mathbf{Y}$ & $\ldots$ \\
\hline MUGCM & On & R21 & 9 & spec & $\ldots$ & $\ldots$ & $\mathrm{Y}$ & $\mathbf{Y}$ & $\mathbf{Y}$ & $\ldots$ \\
\hline MUTM & Off & R21 & 9 & spec & MU & $24 \mathrm{hr}$ & $\mathbf{Y}$ & $\mathbf{Y}$ & $\mathbf{Y}$ & $\ldots$ \\
\hline NCAR & On & $2.8^{\circ}$ & 18 & S-L & $\ldots$ & $\ldots$ & $\ldots$ & $\mathbf{Y}$ & $\mathbf{Y}$ & $\mathbf{Y}$ \\
\hline NIRE & Off & $2.5^{\circ}$ & 15 & S-L & $\mathrm{EC}(92)$ & $6 \mathrm{hr}$ & $\ldots$ & $\ldots$ & $\ldots$ & $\mathrm{Y}$ \\
\hline TM1 & Off & $8 \times 10^{\circ}$ & 9 & slopes & $\mathrm{EC}(79)$ & $12 \mathrm{hr}$ & $\mathbf{Y}$ & $\ldots$ & $\mathbf{Y}$ & $\cdots$ \\
\hline TM2 & Off & $4 \times 5^{\circ}$ & 9 & slopes & $\mathrm{EC}(86)$ & $12 \mathrm{hr}$ & $\ldots$ & $\mathbf{Y}$ & $\mathbf{Y}$ & $\ldots$ \\
\hline TM2Z & Off & $2.5^{\circ}$ & 9 & slopes & EC(90) & $12 \mathrm{hr}$ & $\ldots$ & $\mathrm{Y}$ & $\mathrm{Y}$ & $\ldots$ \\
\hline
\end{tabular}

${ }^{a}$ On-line (full GCMs, all with diurnal cycle except MUGCM) or off-line (driven with externally derived winds).

${ }^{b}$ Resolution, horizontal and vertical (sigma levels except ANU which uses pressure levels).

cAdvection scheme: Lagrangian (Lag), semi-Lagrangian (S-L), spectral (spec), and finite difference schemes (2nd and/or 4th order, slopes [Russell and Lerner, 1981]).

${ }^{\mathrm{d}}$ Wind source for off-line models. EC, ECMWF analyses, the year is given in brackets. Other, GCM data.

eWind frequency. (Stats, subbimonthly data variability is represented statistically.)

fSubgrid parameterizations: horizontal and vertical diffusion, convection, and planetary boundary layer. Note that some schemes may represent more than one process but have been categorized by their primary function. 
variations in vertical diffusion or convection. More detailed descriptions of the models used are given by Rayner and Law [1995, Appendix C].

\section{Results}

Contributing modelers supplied concentration fields for the surface layer, 500 and $200 \mathrm{hPa}$. In addition, zonal mean cross sections were also analysed. Each data set has been normalized such that the January global three-dimensional mean is zero. This accounts for differences in the number of years for which experiments were performed and, to a large extent, any slight differences in net source. We present here only the key results arising out of the submitted data. Rayner and Law [1995] give a more extensive presentation of the results.

\section{Fossil Experiment}

Differences in interhemispheric transport between models can be seen in the zonal annual mean surface concentrations which are shown in Figure 3. While each model gives a broadly similar distribution, with maximum concentrations around $50^{\circ} \mathrm{N}$ and relatively small gradients through the southern hemisphere, there are large differences in the maximum and minimum concentrations. The range of concentrations found for the northern midlatitudes can be reduced by almost half if the Commonwealth Scientific and

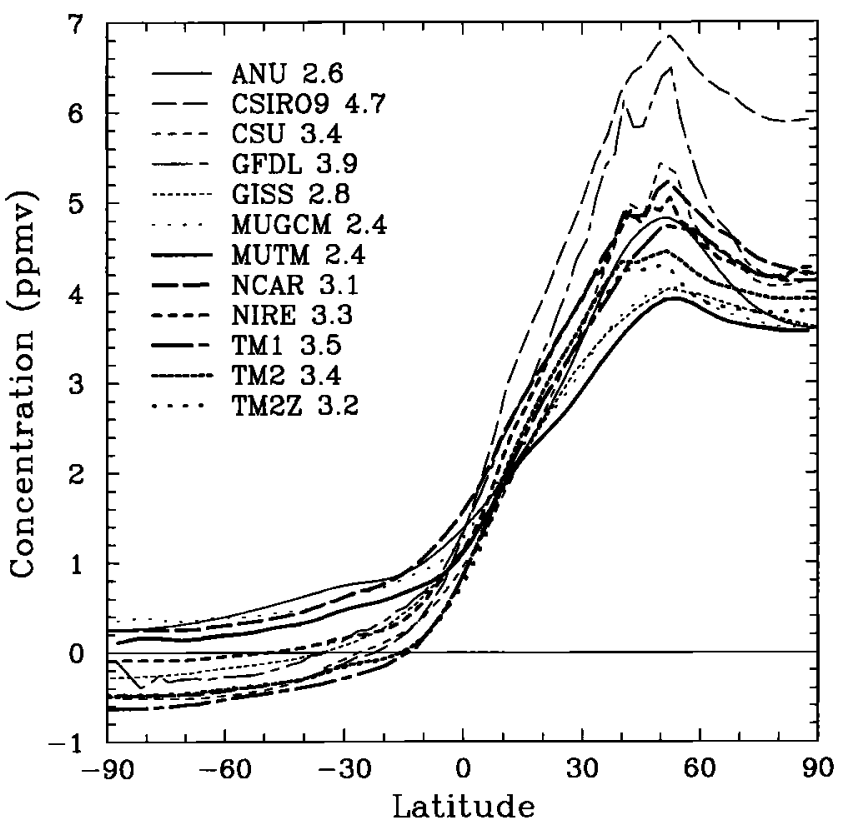

Figure 3. Zonal annual surface mean concentration in parts per million by volume (ppmv) due to fossil emissions. The concentrations have been reduced by the global January mean concentration. The key indicates the model to which the results apply and also gives the concentration difference between the northern and southern hemispheres for that model.
Industrial Research Organization 9 level model (CSIRO9) and GFDL results are excluded. It is likely that this smaller range is more realistic since there have been reported calibrations of meridional mixing using krypton 85 for the GISS and TM1 models [Jacob et al., 1987, Heimann and Keeling, 1989 ], which lie in this group.

The variation among models can be summarized by the interhemispheric concentration difference (northern minus southern hemisphere mean concentration). This is listed alongside each model identifier in the Figure $3 \mathrm{key}$. The interhemispheric differences vary by a factor of 2 . It is important to note that these differences are surface values, and the variation between models reflects differences in both vertical and cross-equatorial transport. We discuss later the exchange times implied by these concentration differences and compare them to vertically integrated exchange times and exchange times calculated from "clean air" rather than zonal mean data.

The CSIRO9 model produces the largest difference (4.7 parts per million by volume (ppmv)), and the Melbourne University (MU) models produce the smallest difference (2.4 ppmv). In order to understand this difference better, MUTM (an off-line model) was run with winds taken from the CSIRO9 model. This simulation produced a surface interhemispheric difference of $3.6 \mathrm{ppmv}$ which indicates that the large-scale winds account for about half the difference between the model results in this case. It appears that the remaining difference is due to slower subgrid scale vertical transport in CSIRO9 than MUTM; in the $\mathrm{CSIRO} 9$ model, $\mathrm{CO}_{2}$ from the surface northern hemisphere source takes longer to reach the upper troposphere where most interhemispheric transport occurs. It should be noted that differences in subgrid scale vertical transport arise both from the different parameterization schemes used in the two models and because of the different numerical diffusion properties of the advection schemes; the MUTM scheme is more diffusive than the semi-Lagrangian scheme used in the CSIRO9 model.

An example of the surface distribution of $\mathrm{CO}_{2}$ is given for the TM2 model in Figure 4. Every model produces high concentrations around Europe, North America, and China associated with regions of high fossil emissions. The major differences among the models occur in the maximum values of these high concentration regions. For example, the GFDL model gives a European maximum of 25.2 ppmv compared to only $6.3 \mathrm{ppmv}$ in the GISS model. Away from the source regions, the variation between models is smaller; concentrations at the locations where $\mathrm{CO}_{2}$ is monitored (the National Oceanic and Atmospheric Administration Climate Monitoring and Diagnostics Laboratory (NOAA/CMDL) network is shown in Figure 4) generally range over about $1 \mathrm{ppmv}$ (excluding CSIRO9 which lies about 1 ppmv higher than any other model in the northern middle and high latitudes). In general, the higher maximum values are produced by the higher resolution models, reflecting their ability to resolve better both the peak values in the source distributions as 


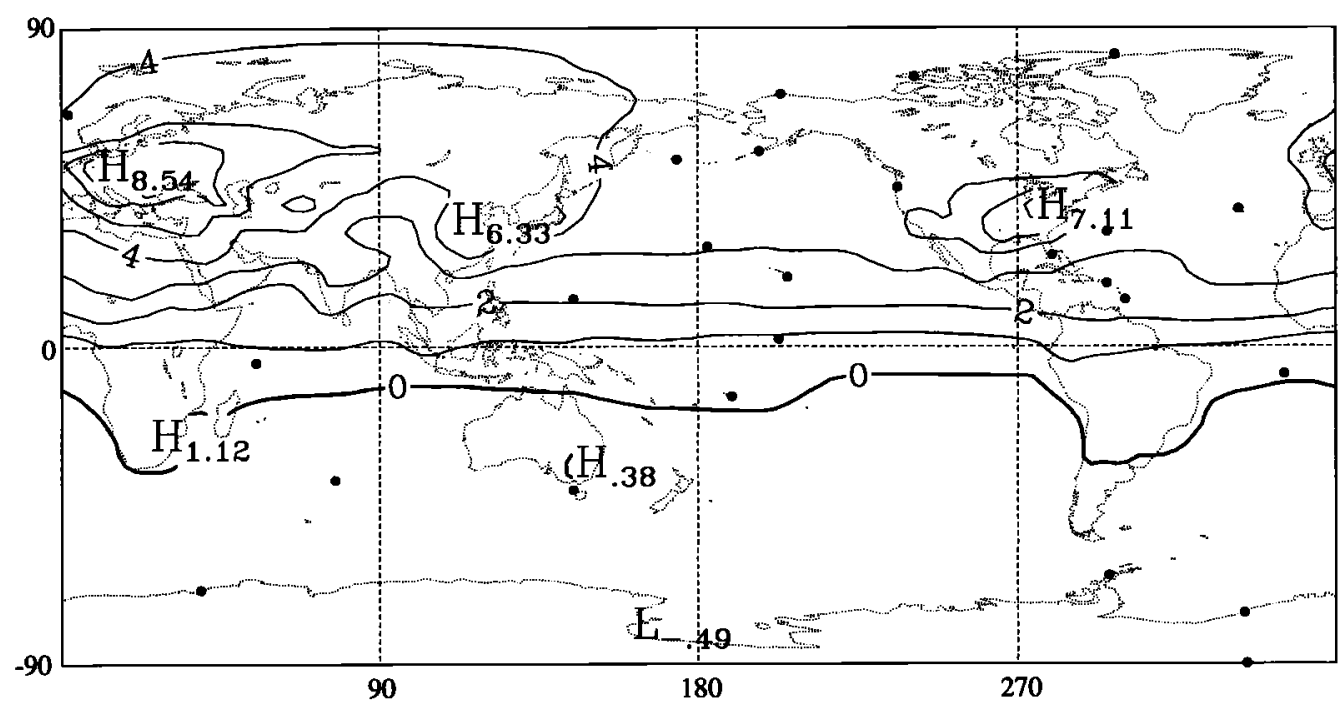

Figure 4. Surface annual mean concentration due to fossil emissions for the TM2 model. The contour interval is $1 \mathrm{ppmv}$. The concentrations have been reduced by the global January mean concentration. The dots indicate the locations of National Oceanic and Atmospheric Administration / Climate Monitoring and Diagnostics Laboratory (NOAA/CMDL) $\mathrm{CO}_{2}$ monitoring sites.

well as smaller scale features in the modeled concentrations. Another factor is the strength of vertical mixing. CSIRO9 appears to have weak vertical mixing throughout the troposphere while GFDL has weak mixing out of its surface layer. In both models, this results in higher surface concentrations.

Vertical gradients in the lower troposphere can be characterized by the surface to $500 \mathrm{hPa}$ concentration difference. The zonal mean of this difference is plotted in Figure 5. There is good qualitative agreement between mod-

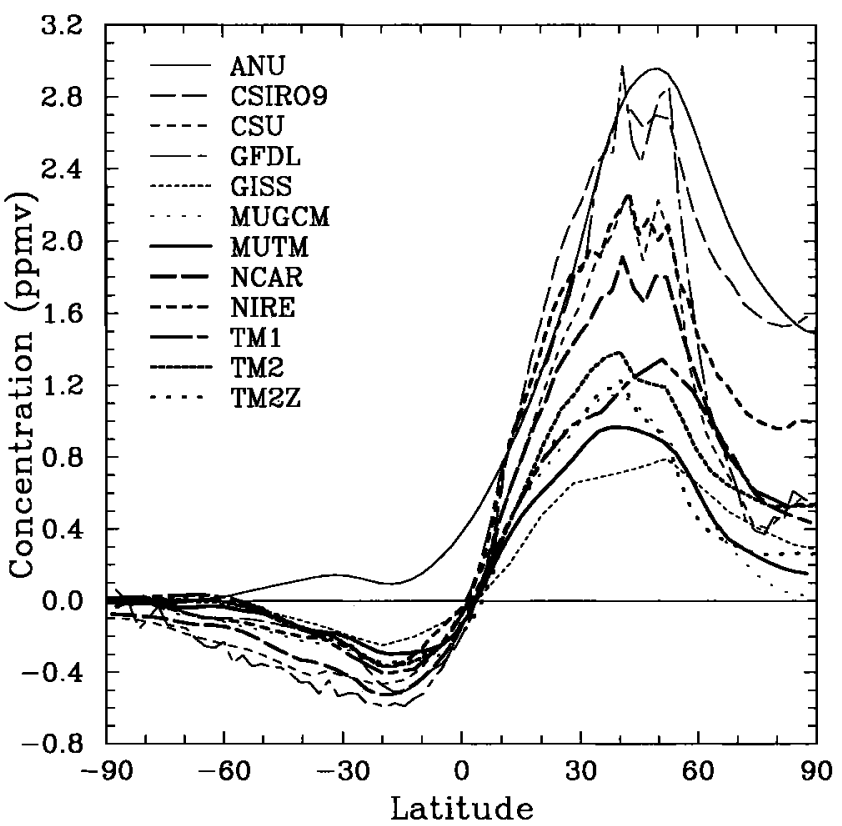

Figure 5. Difference (in ppmv) between the zonal annual surface and $500 \mathrm{hPa}$ concentrations for the fossil experiment. The key indicates the model which applies to each curve. els but a large range in the magnitude of the vertical gradient. All models, except the Australian National University Chemical Transport Model (ANU), produce a region of increasing concentration with height in the southern low latitudes. The increase with height is largest around $10^{\circ}-20^{\circ} \mathrm{S}$ and is associated with high concentration air from the northern hemisphere which is transported southward in the upper troposphere. The largest lower tropospheric gradients occur around $40^{\circ}-60^{\circ} \mathrm{N}$ with a model range of $0.7-3.0 \mathrm{ppmv}$. The larger values tend to occur for those models with higher surface concentrations. The zonal mean $500 \mathrm{hPa}$ concentrations are relatively similar between models (not shown). The zonal mean concentration increases from south to north with a region of more rapid increase through the middle and low latitudes of both hemispheres. Longitudinal variations in concentration at $500 \mathrm{hPa}$ are also small compared to the surface variations.

There is more variety in the model responses at $200 \mathrm{hPa}$ (Figure 6). Approximately half of the models produce maximum concentrations around $0^{\circ}-30^{\circ} \mathrm{N}$ while the remainder have middle to high northern latitude maxima. Nakazawa et al. [1991] measured $\mathrm{CO}_{2}$ concentration between $36^{\circ} \mathrm{N}$ and $30^{\circ} \mathrm{S}$ in the upper troposphere on flights between Tokyo and Sydney and found maximum annual mean concentrations around $0^{\circ}-10^{\circ} \mathrm{N}$. This is more consistent with those models that produce low latitude maxima at $200 \mathrm{hPa}$. However, it is important to note that the observed values are for $\mathrm{CO}_{2}$ from all sources, whereas the modeled results are for the fossil source only. Also, the model data at $200 \mathrm{hPa}$ may include stratospheric air, whereas this has been excluded from the observed data. The ANU model produces a more uniform distribution than the other models. This suggests that there is rapid horizontal mixing acting to reduce the meridional 


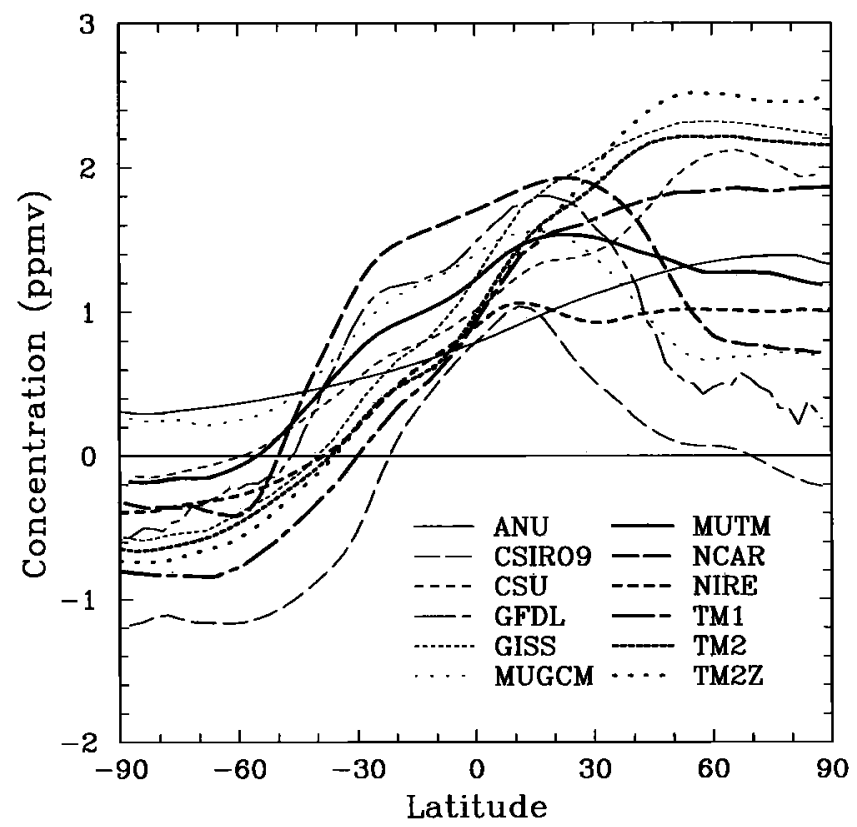

Figure 6. Zonal annual $200 \mathrm{hPa}$ mean concentration (in ppmv) due to fossil emissions. The concentrations have been reduced by the global January mean concentration. The key indicates the model which applies to each line.

gradient. Weak vertical mixing could also contribute, but this is less likely because the ANU $200 \mathrm{hPa}$ global mean concentration is similar to those from other models.

The global distribution of $\mathrm{CO}_{2}$ at $200 \mathrm{hPa}$ is illustrated for the MUGCM case (Figure 7). This is one of the models that gave a low-latitude maximum in the zonal mean. Figure 7 shows maximum concentrations in the west Pacificsoutheast Asian region and around Central America. This is typical of all the models that produced low-latitude max- ima and may be associated with rapid mixing of lower tropospheric air (with high concentrations) to $200 \mathrm{hPa}$ by convection. The models that produced maximum zonal mean concentrations at higher latitudes tended to produce a more zonally uniform global distribution.

\section{Biosphere Experiment}

The seasonal nature of the biospheric source provides many options for characterizing the models' responses. We choose here to focus on the amplitude of the seasonal cycle and the surface annual mean response.

The peak to peak (ptp) amplitudes are calculated as the difference between the maximum and minimum monthly mean concentration at each grid point. The zonal mean ptp amplitude at the surface (Figure 8) increases from around 1-2 ppmv in the southern middle and high latitudes to between 22 and 52 ppmv ( 32 ppmv without CSIRO9 or GFDL) around $65^{\circ} \mathrm{N}$. The larger values produced by CSIRO9 and GFDL are probably due to slow mixing out of the surface layer. This is consistent with the larger meridional gradients produced by these models in the fossil experiment. As in the fossil experiment, the results from the CSIRO9 and MU models are very different. We have also performed the biosphere experiment forcing MUTM with the CSIRO9 winds. The ptp amplitudes that result are almost identical to those produced by MUTM (forced with MUGCM winds), particularly in the northern middle and high latitudes. This suggests that the subgrid scale parameterizations control the amplitude of the seasonal cycles at these latitudes. It is not possible to identify which subgrid scale process is responsible because of their interrelated nature. For example, in MUTM a reduction in convection is partially offset by an increase in transport by vertical diffusion; in the National Institute for Resources and Environment (NIRE) model, the PBL param-

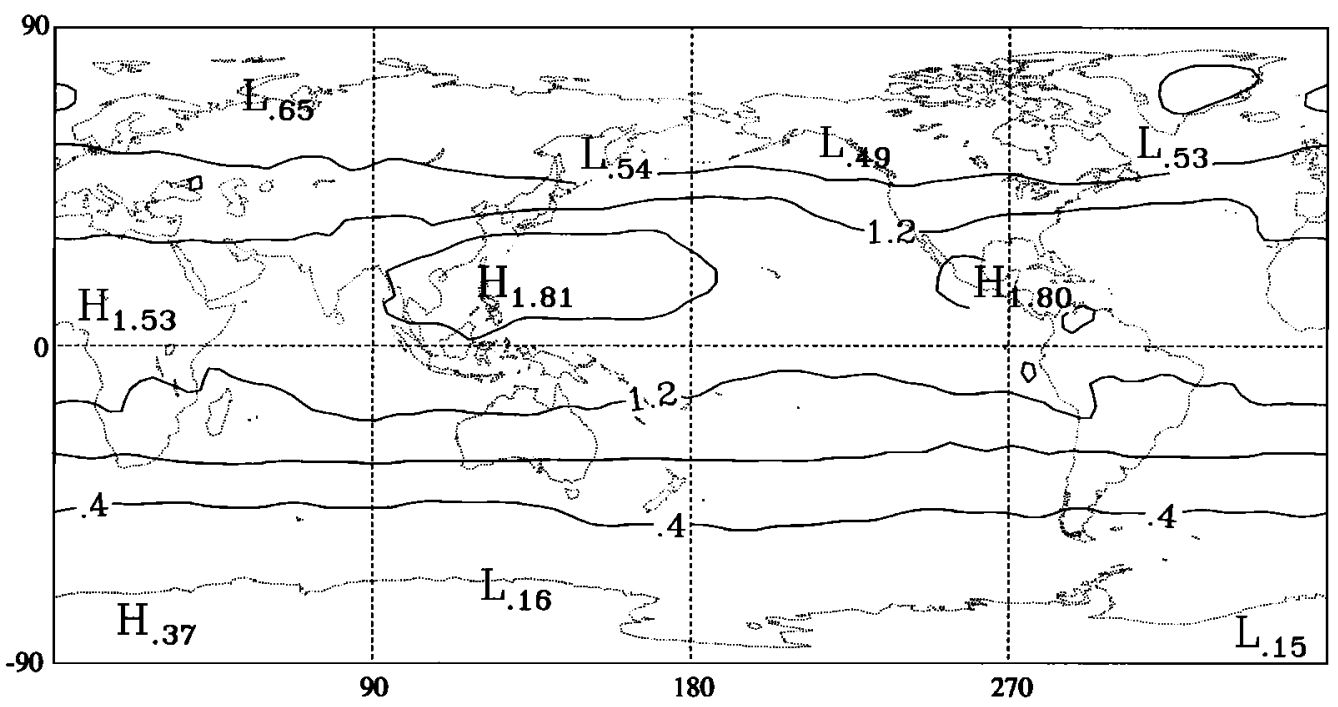

Figure 7. $200 \mathrm{hPa}$ annual mean concentration for the fossil experiment for the Melbourne University General Circulation Model (MUGCM). The contour interval is $0.4 \mathrm{ppmv}$. The concentrations have been reduced by the global January mean concentration. 


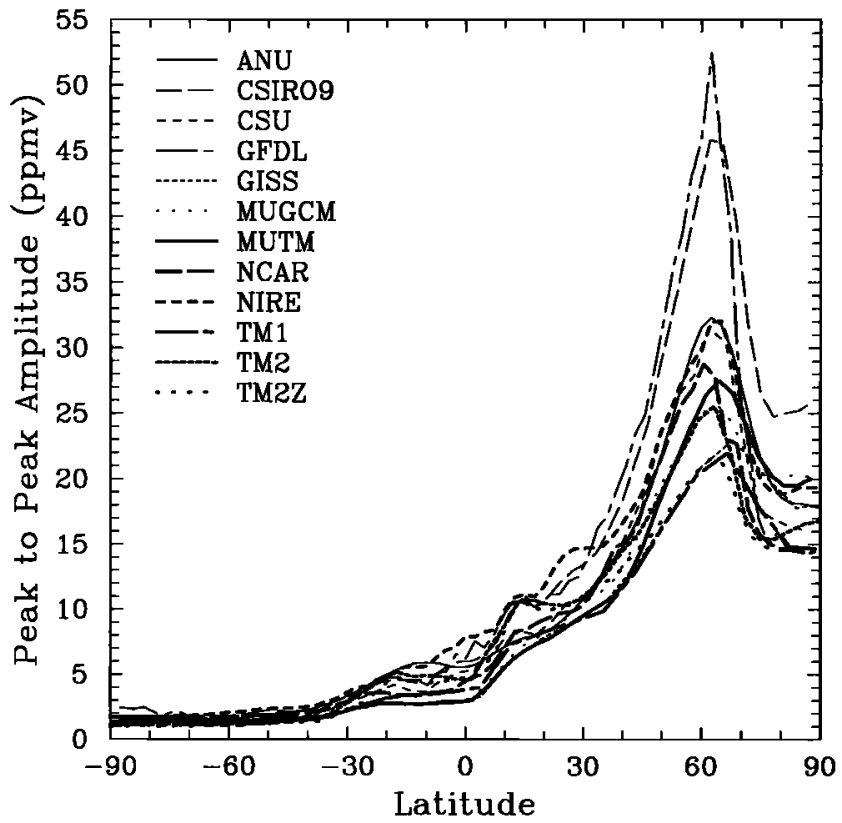

Figure 8. Surface zonal mean peak to peak amplitude (in ppmv) for the biosphere experiment. The key indicates the model that applies to each curve.

eterization appears to compensate for the lack of a convection scheme.

Most models produce surface amplitude distributions that are broadly similar. The distribution produced by the Colorado State University (CSU) model is shown in Figure 9. Land regions have higher amplitudes than ocean regions at the same latitude (except North Africa). The maximum amplitudes occur in regions of large seasonality in the sources (northern Eurasia, Alaska, China, India, tropical Africa, and South America). There is some disagreement between mod- els on the relative magnitudes of these maxima, but the Eurasian amplitudes are usually the largest. These Eurasian maxima range from $30 \mathrm{ppmv}$ in the GISS model to $112 \mathrm{ppmv}$ in the GFDL model. The larger amplitudes tend to occur in the higher-resolution models but, in contrast to the fossil experiment, vertical resolution and associated vertical subgrid scale processes appear to be more important than horizontal resolution. This is not surprising since the biosphere sources were given on a $4^{\circ} \times 5^{\circ}$ grid which should be well resolved by all but the lowest resolution models. The importance of the vertical resolution and processes is supported by an experiment by S. Taguchi (personal communication, December 1995) with the NIRE model. Vertical diffusion strength was increased by increasing the depth of the model's planetary boundary layer by $50 \mathrm{hPa}$. The resulting maximum ptp amplitude over China was 43 ppmv compared to 94 ppmv in the original simulation.

While there are difficulties associated with comparing modeled and observed amplitudes, such comparisons can assist in model evaluation, especially in the northern extratropics where the biosphere is the major contributor to seasonality [Heimann et al., 1989]. We focus on this region in a comparison of modeled and observed amplitudes at monitoring sites. As each model uses a different grid, the four nearest grid points to a monitoring site are used to interpolate to the actual location. This method does not take any account of the practice at continental coastal sites of measuring $\mathrm{CO}_{2}$ from marine air, so comparison with the observations at these sites must be done with caution. We compare (Figure 10) modeled ptp amplitudes for 15 NOAA/CMDL monitoring sites, listed in Table 2 and plotted in Figure 9, with observed amplitudes given by Conway et al. [1994b].

Depending on the site, the range of modeled amplitudes varies; at Guam (GMI), the model range is about 4 ppmv

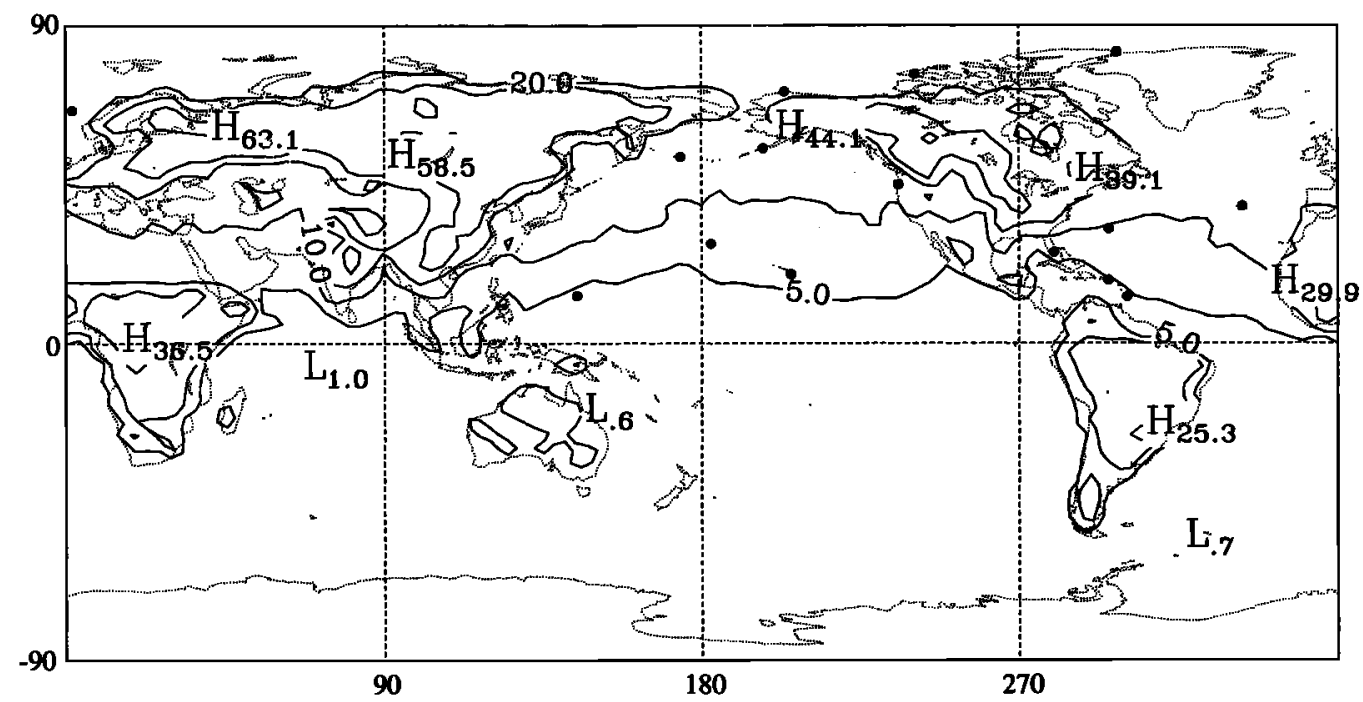

Figure 9. Surface peak to peak amplitude for the biosphere experiment from the Colorado State University (CSU) model. The contours are 5, 10,20,30, and $50 \mathrm{ppmv}$. The dots indicate the locations of the NOAA/CMDL monitoring sites for which data are presented in Figure 10. 


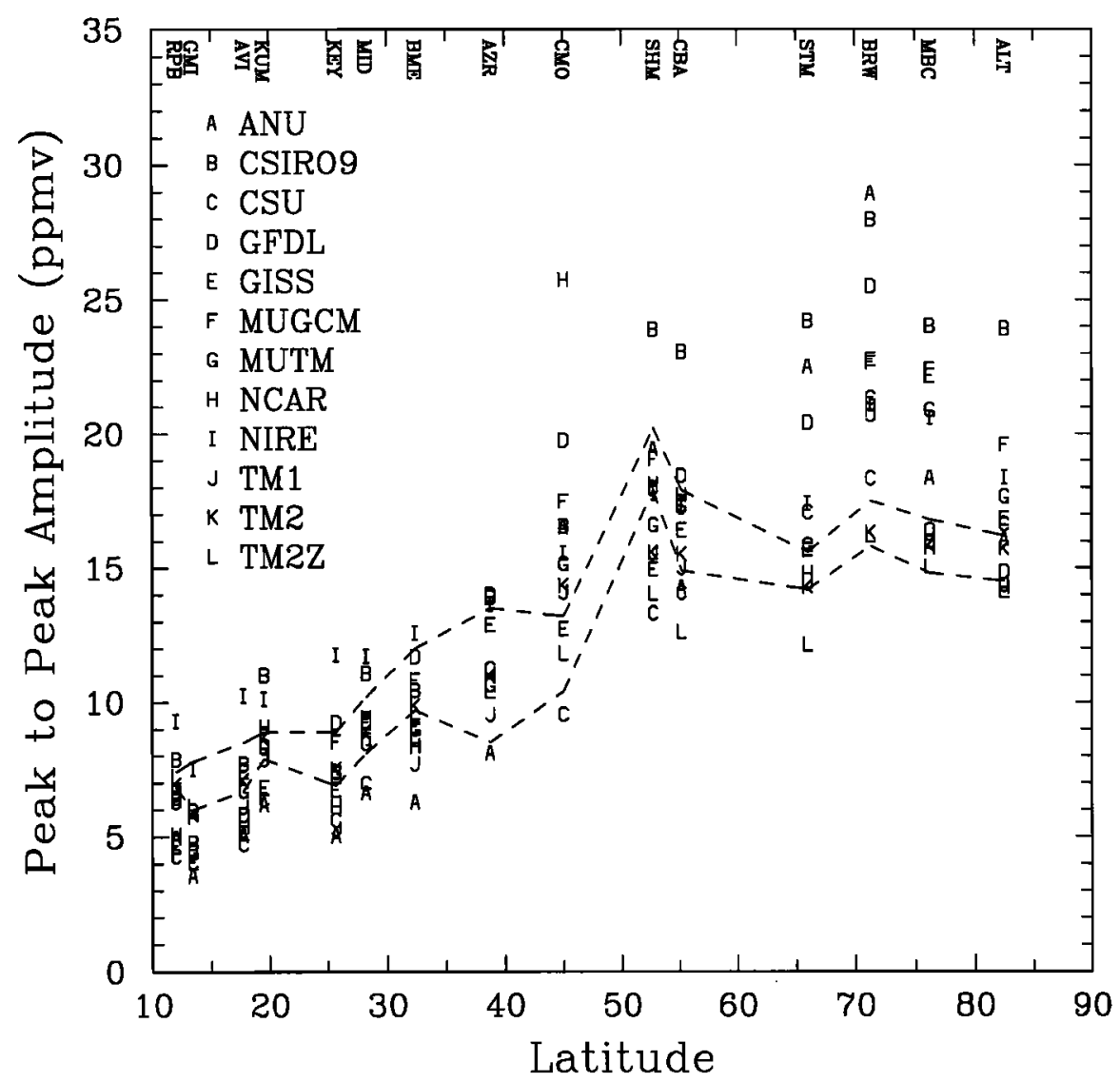

Figure 10. Peak to peak amplitude (in ppmv) at 15 northern hemisphere monitoring sites in the NOAA/CMDL network. The sites are identified at the top of the graph using the codes given in Table 2. The letter that applies to each model is indicated by the key. The dashed lines represent the \pm 1 standard deviation spread of the observed values (taken from Figure 10 of Conway et al. [1994b]). Lines have been used only for clarity not because it is realistic to connect the values from different sites. Also for clarity, the Ragged Point (RPB) data have been shifted slightly to the south so that they do not overlay the Guam (GMI) data.

compared to around 15 ppmv at Cape Meares (CMO). However, the model range for the monitoring sites is smaller than the range seen in the zonal means. With the exception of TM2 and TM2Z, all models overestimate the amplitude (taken here to mean they lie above the upper observation value) at one or more of the four northernmost sites. Some sites are close to land, and this may have an impact since we are comparing model data for all times with observed data selected for "background" conditions. A data selection test using MUTM data indicated that the amplitude at Barrow could be reduced by 2 ppmv but that amplitudes at Mould Bay and Alert did not change significantly. This suggests that there may be some problems with the input source in this region, as it seems unlikely that transport errors would consistently overestimate the amplitudes across so many models.

The models perform reasonably well for Cold Bay; with the exception of the CSIRO9 and TM2Z models, all the amplitudes are within about $1 \mathrm{ppmv}$ of the observed range. At
Shemya, most models underestimate the amplitude, while at Cape Meares the modeled amplitude is generally greater than observed. This site is one at which data selection could be expected to reduce the modeled amplitude. At the middle and low-latitude sites, the models normally span the observations. The NIRE model is typically near the top of the range of model results (possibly because it does not include tracer transport due to convection), while the ANU and CSU models are at the low end of the range.

One of the larger range of amplitudes in Figure $10 \mathrm{oc}-$ curred at Barrow. Figure 11 shows the surface monthly mean concentration for each model at this site. Also shown is the observed seasonal cycle represented by the first two harmonics fitted to detrended data from Conway et al. [1994a]. In general, there is a good agreement between models in the structure of the seasonal cycle, although there are large discrepancies in the magnitudes of the maximum and minimum concentrations. The comparison with the observed seasonal cycle is not as good. All models produce a maximum value 
Table 2. Site Locations Used for Comparing Modeled and Observed Seasonal Cycles

\begin{tabular}{llcc}
\hline Code & \multicolumn{1}{c}{ Station } & Latitude & Longitude \\
\hline ALT & Alert & $82.5^{\circ} \mathrm{N}$ & $297.7^{\circ} \mathrm{E}$ \\
AVI & St. Croix & $17.8^{\circ} \mathrm{N}$ & $295.3^{\circ} \mathrm{E}$ \\
AZR & Azores & $38.8^{\circ} \mathrm{N}$ & $332.9^{\circ} \mathrm{E}$ \\
BME & Bermuda East & $32.4^{\circ} \mathrm{N}$ & $295.4^{\circ} \mathrm{E}$ \\
BRW & Barrow & $71.3^{\circ} \mathrm{N}$ & $203.4^{\circ} \mathrm{E}$ \\
CBA & Cold Bay & $55.2^{\circ} \mathrm{N}$ & $197.3^{\circ} \mathrm{E}$ \\
CMO & Cape Meares & $45.0^{\circ} \mathrm{N}$ & $236.0^{\circ} \mathrm{E}$ \\
GMI & Guam & $13.4^{\circ} \mathrm{N}$ & $144.8^{\circ} \mathrm{E}$ \\
KEY & Key Biscayne & $25.7^{\circ} \mathrm{N}$ & $279.8^{\circ} \mathrm{E}$ \\
KUM & Kumakahi & $19.5^{\circ} \mathrm{N}$ & $205.2^{\circ} \mathrm{E}$ \\
MBC & Mould Bay & $76.2^{\circ} \mathrm{N}$ & $240.7^{\circ} \mathrm{E}$ \\
MID & Sand Is. & $28.2^{\circ} \mathrm{N}$ & $182.6^{\circ} \mathrm{E}$ \\
RPB & Ragged Point & $13.2^{\circ} \mathrm{N}$ & $300.6^{\circ} \mathrm{E}$ \\
SHM & Shemya & $52.8^{\circ} \mathrm{N}$ & $174.1^{\circ} \mathrm{E}$ \\
STM & Station M & $66.0^{\circ} \mathrm{N}$ & $2.0^{\circ} \mathrm{E}$ \\
\hline
\end{tabular}

which is too large and occurs too late and winter concentrations which are too low. Some of these differences may be reduced if the model data is selected for marine air. The August-November period is reasonably simulated. Since all the models are producing similar errors, this suggests an error with the input sources rather than with the model transport, particularly, as similar discrepancies are seen at most

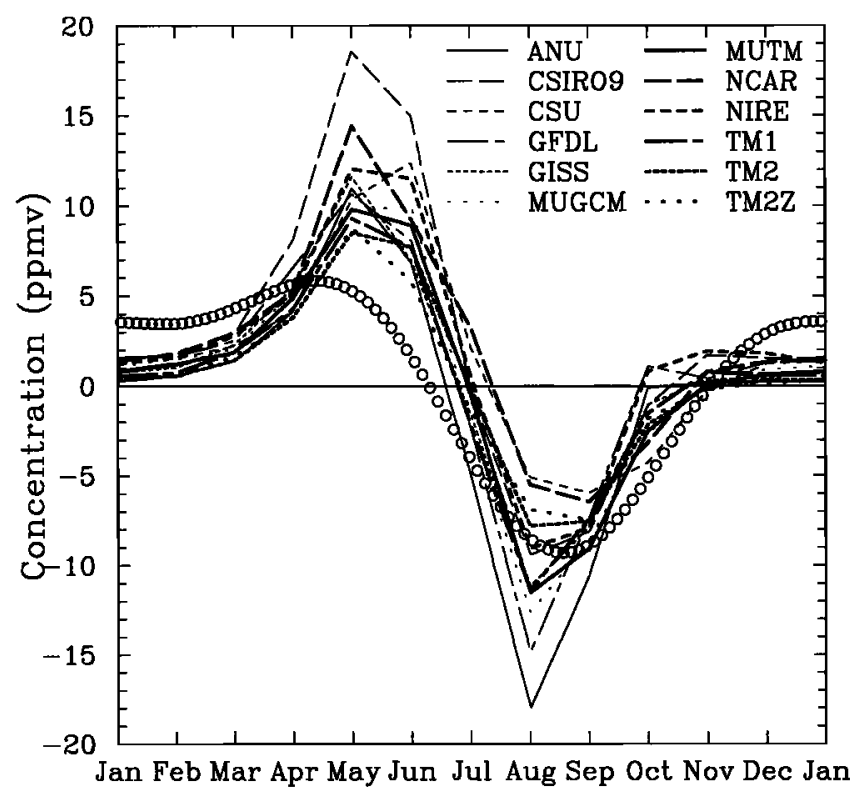

Figure 11. Monthly surface mean concentration (in ppmv) at Barrow $\left(71^{\circ} \mathrm{N}, 203^{\circ} \mathrm{E}\right)$ for the biosphere experiment. The concentrations have been reduced by the global January mean concentration. The curve that applies to each model is indicated by the key. The observed seasonal cycle is shown by the circles. of the high northern latitude sites. I. Fung (personal communication, August 1995) has indicated that low light and long path lengths result in errors in the normalized difference vegetation index (NDVI) (and hence $\mathrm{CO}_{2}$ fluxes) at high latitudes in spring. There may also be errors in the respiration estimates through the use of air temperatures rather than soil temperatures. The above comparison illustrates the potential extra information that can be gained by running a range of transport models: had only one result been available it would be more difficult to distinguish between source and transport errors.

While the annual mean biospheric source is zero everywhere, this is not true of the spatial distribution of annual mean concentration resulting from this source. The interaction of seasonal variations in transport with the seasonal source produces nonzero annual mean concentrations. The zonal annual mean at the surface (Figure 12) shows that for some models (CSIRO9, CSU, GFDL, National Center for Atmospheric Research (NCAR), and NIRE) the north-south gradient is around half that produced in the fossil experiment. Most models produce small positive concentrations around $5^{\circ} \mathrm{N}$. These result from the seasonal shift of the Intertropical Convergence Zone (ITCZ). The positive concentrations in the northern midlatitudes appear to be associated with seasonality in vertical transport.

Monthly northern hemisphere concentrations (not shown) are clearly higher between November and May for the "large gradient" models than for the "small gradient" ones. Since the difference occurs on a hemispheric scale, this supports

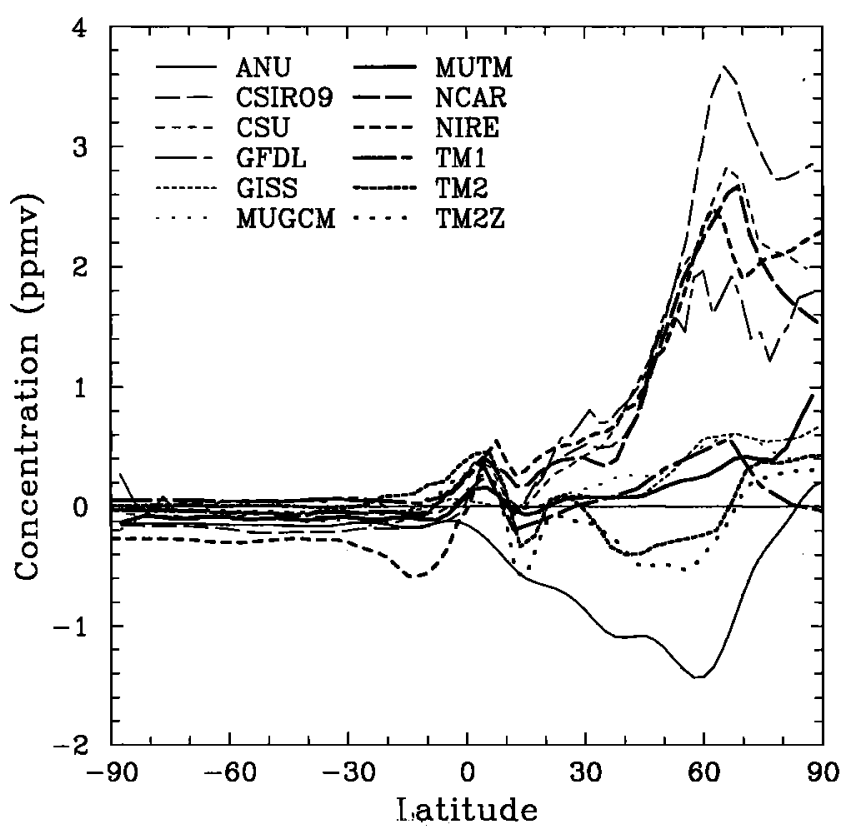

Figure 12. Surface zonal annual mean concentration (in ppmv) for the biosphere experiment. The concentrations have been reduced by the global January mean concentration. The curve that applies to each model is indicated by the key. 
the contention that vertical transport is the important process and that differences in vertical transport between models in winter may be critical. It appears that both resolved and subgrid scale vertical transport are important, possibly depending on the model used. For example, experiments with MUTM have shown that seasonality of convection is largely responsible for the positive annual mean in the northem midlatitudes in this model, while Denning et al. [1995] found correlations between sources and the depth of the PBL to be a major factor. The ANU model annual mean is rather different from the other models. J. Taylor (personal communication, May 1995) has indicated that the negative concentrations result from the use of 1980 winds at only 7 levels; small positive concentrations were obtained in subsequent experiments when winds from the 1990s at 14 or 15 levels were used.

Many of the differences between models seen in the surface layer are attenuated with height. At $500 \mathrm{hPa}$, the models give similar results for the amplitude of the seasonal cycle. The zonal mean amplitude (not shown) is small and relatively uniform through the southern hemisphere and then increases to $12-14 \mathrm{ppmv}$ at the north pole. The $500 \mathrm{hPa}$ distributions show a number of common features. Higher amplitudes are found in the Himalayan region, presumably reflecting the proximity of $500 \mathrm{hPa}$ to the surface. A second common feature is higher amplitudes to the east of the southern African and South American continents, indicating transport of continental air over the oceans.

At $200 \mathrm{hPa}$, differences between models reemerge. The zonal mean ptp amplitudes (Figure 13) are similar through the southern hemisphere but vary widely in the northern

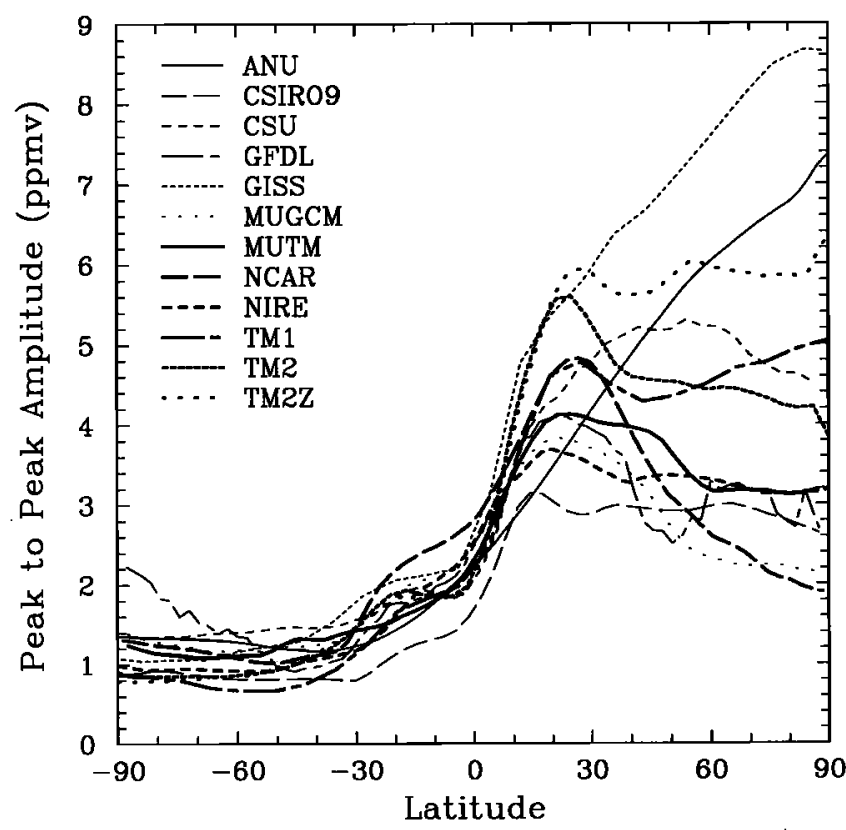

Figure 13. The 200-hPa, zonal mean peak to peak amplitude (in ppmv). The curve that applies to each model is indicated by the key. hemisphere. Nakazawa et al. [1991] observed upper tropospheric amplitudes at approximately $150^{\circ} \mathrm{E}$ of $2-3 \mathrm{ppmv}$ between $30^{\circ} \mathrm{S}$ and the equator increasing to almost $8 \mathrm{ppmv}$ at $36^{\circ} \mathrm{N}$. These amplitudes are generally larger than those produced by the models, both in the zonal mean and at $150^{\circ} \mathrm{E}$. It is likely that the models are sampling both tropospheric and stratospheric air at this level which results in smaller amplitudes because the seasonal cycle in the lower stratosphere is smaller than and out of phase with the upper tropospheric cycle [Nakazawa et al., 1991].

The 200-hPa global distributions (not shown) produce some differences and some common features. Large amplitudes are found in the India-China region in many models. All models give some regions, predominantly tropical, where the amplitudes are higher at $200 \mathrm{hPa}$ than at $500 \mathrm{hPa}$. This may result from rapid lifting of lower tropospheric air by convection followed by horizontal advection.

\section{Discussion}

\section{Large-Scale Transport and Source Estimates}

A simple way to characterize the large-scale transport properties of the various models is by their exchange times. The exchange time is defined as the difference in inventory of two boxes divided by the flux between them. In these experiments, where sources and growth rates (and hence fluxes) are equal for all models, we can use the equivalent definition of the difference in concentration between two boxes divided by half the difference in source strength between them, that is,

$$
\tau=2 \frac{q_{n}-q_{s}}{S_{n}-S_{s}}
$$

where $\tau$ is exchange time, $q$ is mixing ratio, $S$ is source, and the subscripts refer to northern and southern hemisphere. Sources are expressed as concentration trends per hemisphere per year. We use the annual mean concentration from the fossil experiment for these calculations.

There is a wide variety of partitions of the atmosphere available for a calculation of exchange times. Two such choices are displayed in Table 3, namely, hemispheric surface means and hemispheric three-dimensional means. The surface mean is calculated in two ways. In the surface column we use the mean from all supplied surface data in a hemisphere, while in the station column we use data from the $\mathrm{CO}_{2}$ observational network. This second mean is calculated by fitting a smoothing spline [Enting, 1987] to the annual mean concentrations interpolated to the sites plotted in Figure 4. The hemispheric means are then the area-weighted means of these splined values. The fitting is performed in the sine of latitude, and the $50 \%$ attenuation length scale is 1. The exchange time calculated by the second method is perhaps more relevant to carbon cycle inversions in which the station data is the input. 
Table 3. Interhemispheric Exchange Times in Years

\begin{tabular}{lccc}
\hline \multicolumn{1}{c}{ Model } & Surface & Station & Vertical \\
\hline ANU & 1.16 & 0.91 & $\ldots$ \\
CSIRO9 & 2.14 & 1.92 & 1.16 \\
CSU & 1.54 & 1.29 & 0.99 \\
GFDL & 1.76 & 1.53 & 0.82 \\
GISS & 1.26 & 1.14 & 0.90 \\
MUGCM & 1.06 & 1.00 & 0.58 \\
MUTM & 1.06 & 0.99 & 0.66 \\
NCAR & 1.38 & 1.21 & $\ldots$ \\
NIRE & 1.50 & 1.38 & 0.92 \\
TM1 & 1.58 & 1.47 & 1.20 \\
TM2 & 1.52 & 1.38 & $\ldots$ \\
TM2Z & 1.46 & 1.36 & 1.06 \\
\hline
\end{tabular}

The exchange time is calculated, from the fossil experiment, as the difference in mean concentration between two boxes divided by half the difference in source strength between them. Three models did not supply sufficient data to calculate a vertically integrated exchange time.

The first thing to note about Table 3 is the wide range of transport efficiencies demonstrated throughout. This reinforces the impression given by Figure 3. Comparing the surface and station columns shows that, while using data at sampling locations reduces the large-scale gradient, it does not reduce the differences in these gradients among models. The station column does suggest a slight reordering of model exchange times with ANU replacing MUTM as the model with the fastest exchange. Also, the GFDL model is now the slowest of a cluster of models rather than a clear outlier. Finally, CSIRO9, under this measure, has an exchange time almost $30 \%$ larger than the next model.

Comparison of the surface column and the vertical mean column indicates great variety in the ratio of surface and vertically integrated exchange. For example, the GFDL model, which shows the second slowest exchange between surface boxes, has the third quickest exchange between vertically integrated hemispheric boxes. Also, among the three models which supplied cross-section data and used analyzed winds from the European Centre for Medium-Range Weather Forecasting (ECMWF), the surface exchange times are more closely grouped than the vertical mean exchanges. Both of these suggest considerable differences in rates of vertical transport, which is supported by the range of surface to $500 \mathrm{hPa}$ differences shown in Figure 5. The complex relationship between surface and three-dimensional behavior also suggests that surface observations do not determine well the three-dimensional fields and fluxes. This is less important for $\mathrm{CO}_{2}$ where most important sources and observations occur at the surface than for other species with more active chemistry.
It is worth relating the differences in large-scale horizontal exchange rates evident in Table 3 to carbon budgets derived from such models. At the simplest and broadest level, we can write a first-order two-box model such as

$$
\begin{aligned}
& \frac{\partial q_{n}}{\partial t}=S_{n}-\frac{q_{n}-q_{s}}{\tau} \\
& \frac{\partial q_{s}}{\partial t}=S_{s}-\frac{q_{s}-q_{n}}{\tau}
\end{aligned}
$$

where $q$ refers to mixing ratios, $S$ refers to sources, $\tau$ is the exchange time, and the subscripts refer to northern and southern hemisphere.

Differencing these two equations and assuming steady state yields

$$
S_{-}=\frac{2 q_{-}}{\tau}
$$

where the subscript refers to interhemispheric differences.

Since the measured concentrations are at the surface, the mixing ratios and exchange times are those for the surface boxes. These exchange times, calculated from the fossil experiment, relate differences in hemispheric sources to the interhemispheric difference. The same relationship should hold, to a first approximation, between the total source in the real atmosphere and the observed interhemispheric difference. This neglects variations in response to seasonal sources such as are shown in Figure 12. Using the exchange times enumerated in the surface column of Table 3 and then applying the range of values to a nominal observed interhemispheric difference of $2 \mathrm{ppmv}$ gives a range in the distribution of the net source of $1.9-3.8 \mathrm{Gt} \mathrm{C} \mathrm{yr}^{-1}$, that is, roughly $3 \pm 1 \mathrm{Gt} \mathrm{C} \mathrm{yr}^{-1}$. The sum of the two hemispheric sources must agree with the change in global inventory, approximately $3 \mathrm{Gt} \mathrm{C} \mathrm{yr}^{-1}$ through the 1980s. These two constraints combine to give

$$
\begin{aligned}
& S_{n}=3 \pm 0.5 \mathrm{Gt} \mathrm{C} \mathrm{yr}^{-1} \\
& S_{s}=0 \pm 0.5 \mathrm{Gt} \mathrm{C} \mathrm{yr}^{-1}
\end{aligned}
$$

The uncertainty in these $\mathrm{CO}_{2}$ source estimates arises only from uncertainties in transport for a perfectly known gradient; uncertainties in the $\mathrm{CO}_{2}$ distribution will compound it.

Three issues arise from the above analysis. The first is the direct comparison of source uncertainties arising from transport with other uncertainties in carbon budgets. Our error in hemispheric source due to transport uncertainty is comparable to that quoted by Schimel et al. [1995] for the input due to fossil fuel combustion $\left(0.5 \mathrm{Gt} \mathrm{C} \mathrm{yr}^{-1}\right)$. If the error in perturbation ocean uptake $\left(0.8 \mathrm{Gt} \mathrm{C} \mathrm{yr}^{-1}\right)$ is distributed evenly between hemispheres, it also produces errors comparable to those arising from transport. Quoted errors in the terrestrial fluxes are considerably larger than all of these.

Second, the range of interhemispheric source gradients allowed by TransCom cannot explain the differences in global budgets from previous studies. Keeling et al. [1989] and Tans et al. [1990] suggested different global carbon budgets. 
Keeling et al. [1989] proposed an ocean uptake greater than $2 \mathrm{Gt} \mathrm{C} \mathrm{yr}^{-1}$, while Tans et al. [1990] estimated an ocean uptake less than $1 \mathrm{Gt} \mathrm{C} \mathrm{yr}^{-1}$. These studies used transport models to verify that proposed source distributions matched observed concentration distributions. The transport models (TM1 and GISS) have quite similar large-scale transport properties. (It is noteworthy that both models have been calibrated with other observed tracers, so we may have some confidence in their large-scale transport.) This similarity of transport means that the total source integrated over a hemisphere is similar in each study. The partition of global fluxes between land and ocean is determined by other factors than transport, for example, the box model used by Keeling et al. [1989]. Other observations, for example, over continents, are needed for transport modeling to settle the discrepancy.

Enting et al. [1995], in their synthesis inversion, also found that inversion of atmospheric transport, coupled to the current observational network, was not a strong constraint on global budgets. For example, they found that global ocean uptake was controlled mainly by global budgets of total carbon and ${ }^{13} \mathrm{C}$. Knowledge of the spatial structure of $\mathrm{CO}_{2}$ played a secondary role. The extra uncertainty in modeled transport implied by our intercomparison would hence have a secondary effect on global flux estimates. Such reasoning does not hold for hemispheric or regional scales.

The third point arising from our budget analysis concerns model differences we neglected, in particular, the response to seasonal sources. Both the TM1 and GISS models produced little zonal annual mean response to the biospheric source. A budget produced by the CSU model, for example, would require a larger sink in the northern middle and high latitudes. This was demonstrated by Denning et al. [1995]. We also neglected the importance of the position of our source within a hemisphere. A source of equivalent size to the fossil fuel source but in the northern tropics would produce a smaller interhemispheric concentration difference and hence exchange time.

\section{Reducing Uncertainties}

Previous sections have highlighted the range of responses to equivalent sources among a range of transport models. We have also seen that this may have significant impact on our ability to distribute net sources spatially. This naturally raises the question of what to do to reduce the uncertainty. Three nonexclusive paths seem apparent which may offer mutual confirmation. The first is to use a consensus of models as some guidance to the behavior of the real atmosphere. It is noteworthy that about half the range seen in surface exchange times in the surface column of Table 3 or gradients in Figure 3 is supplied by two models, GFDL and CSIRO9. Also, model consensus casts doubt on the reversed gradient seen in the annual mean surface response to the biotic source in the ANU model. The same approach is implicit in our comments on the biotic source itself; the inability of the seasonal cycle of any model to match the observations suggests problems with the veracity of the source estimate.
Another approach is to use tracers with known sources and structure. Typically, chlorofluorocarbons (CFCs) and krypton 85 have been used to assess interhemispheric transport while radon 222 has been used to assess vertical transport. Both are important; the fossil experiment has shown that models can produce very similar surface distributions but very different distributions in the upper troposphere. Reproducing the surface distributions of CFCs or krypton 85 may, then, only constrain one aspect of the transport. The importance of constraining the vertical transport can also be seen from a comparison of the surface column and the vertical mean column of Table 3 . The two outlying models, CSIRO9 and GFDL, produce the largest ratios of surface to vertically integrated exchange times, suggesting their different behavior arises from differences in vertical transport. Thus a good calibration of vertical transport (e.g., vertical profiles for a number of locations and seasons) would be a strong discriminator among models.

For any proposed calibration tracer, uncertainties in the sources and the relatively sparse observations, spatially or temporally, mean that calibration is not an easy task. For example, Prather et al. [1995] report an intercomparison of 20 two- and three-dimensional model simulations of radon and find a good agreement between "established" threedimensional models but comment on the sparsity of observations available to test the model predictions. Despite these difficulties, calibration tracers should prove useful in validating model transport.

A third approach is to isolate and verify those aspects of model performance thought to be influential on $\mathrm{CO}_{2}$ transport. Such calculations have been carried out by, for example, Fung et al. [1983], Taguchi [1994], and Denning et al. [1995]. It is intended to combine approaches two and three in a second phase of the TransCom project in which a calibration tracer, $\mathrm{SF}_{6}$, will be used and detailed flux diagnostics will be retained for comparison. This should allow a mechanistic understanding of the differences in modeled transport.

\section{Conclusions}

We have compared the simulation of $\mathrm{CO}_{2}$ concentration due to fossil fuel emissions and biospheric exchange by 12 atmospheric tracer transport models. While each model produces broadly similar concentration distributions, there is a large range in the efficiency of transport among models. For example, surface interhemispheric exchange times vary by a factor of 2, although half this range is contributed by only two models. There is also wide variance among models on the annual mean response to the biosphere exchange.

The implications of these results for $\mathrm{CO}_{2}$ budget studies are significant. The quoted factor of 2 variation in exchange times translates to an extra uncertainty in hemispheric carbon budgets comparable to that quoted by the Intergovermental Panel on Climate Change for fossil fuel or ocean uptake and smaller than for terrestrial fluxes. Uncertainties in transport can also be expected to have an impact on the mod- 
eling of other chemical species in the atmosphere, whenever the lifetime is long enough that transport affects the distribution of the species. More detailed observations of $\mathrm{CO}_{2}$ and other species, particularly on the continents and aloft, can play a major role in constraining both transport and net sources.

Acknowledgments. This study was carried out with support from the Australian Government Cooperative Research Centres Programme. P. Rayner thanks the Program in Atmospheric and Oceanic Sciences at Princeton University for support in the early stages of this study. M. Ramonet thanks P. Bousquet for help with running the TM2Z simulations. S. Piper acknowledges support from NASA grant NAGW-2987, Electric Power Research Institute grant RP8011-20, the San Diego Supercomputer Center, and the Scripps supercomputer block grant administered by Steven Constable, and he thanks C.D. Keeling for facilitating modeling work over the years. We have appreciated helpful comments on this manuscript from I. Enting and I. Smith.

\section{References}

Ciais, P., P. P. Tans, J. W. C. White, M. Trolier, R. J. Francey, J. A. Berry, D. R. Randall, P. J. Sellers, J. G. Collatz, and D. S. Schimel, Partitioning of ocean and land uptake of $\mathrm{CO}_{2}$ as inferred by $\delta^{13} \mathrm{C}$ measurements from the NOAA Climate Monitoring and Diagnostics Laboratory Global Air Sampling Network, J. Geophys. Res., 100, 5051-5070, 1995.

Conway, T. J., P. P. Tans, and L. S. Waterman, Atmospheric $\mathrm{CO}_{2}$ records from sites in the NOAA/CMDL air sampling network, in Trends '93: A Compendium of Data on Global Change, edited by T. Boden, D. Kaiser, R. Sepanski, and F. Stoss, pp. 41-119, Carbon Dioxide Inf. Anal. Cent., Oak Ridge Natl. Lab., Oak Ridge, Tenn., 1994a.

Conway, T. J., P. P. Tans, L. S. Waterman, K. W. Thoning, D. R. Kitzis, K. A. Masarie, and N. Zhang, Evidence for interannual variability of the carbon cycle from the National Oceanic and Atmospheric Administration/Climate Monitoring and Diagnostics Laboratory Global Air Sampling Network, J. Geophys. Res., 99, 22,831-22,855, 1994b.

Denning, A. S., I. Y. Fung, and D. A. Randall, Gradient of atmospheric $\mathrm{CO}_{2}$ due to seasonal exchange with land biota, Nature, 376, 240-243, 1995.

Enting, I. G., On the use of smoothing splines to filter $\mathrm{CO}_{2}$ data, $J$. Geophys. Res., 92, 10,977-10,984, 1987.

Enting, I. G., C. M. Trudinger, R. J. Francey, and H. Granek, Synthesis inversion of atmospheric $\mathrm{CO}_{2}$ using the GISS tracer transport model, Tech. Pap. 29, 44 pp., Div. of Atmos. Res., Commonw. Sci. Ind. Res. Organ., Aspendale, Victoria, Australia, 1993.

Enting, I. G., T. M. L. Wigley, and M. Heimann, Future emissions and concentrations of carbon dioxide: Key ocean/atmosphere/land analyses, Tech. Pap. 31, 118 pp., Div. of Atmos. Res., Commonw. Sci. Ind. Res. Organ., Aspendale, Victoria, Australia, 1994.

Enting, I. G., C. M. Trudinger, and R. J. Francey, A synthesis inversion of the concentration and $\delta^{13} \mathrm{C}$ of atmospheric $\mathrm{CO}_{2}$, Tellus, Ser. $B, 47,35-52,1995$.

Erickson, D. J., III, P. J. Rasch, P. P. Tans, P. Friedlingstein, P. Ciais, E. Maier-Reimer, K. Six, C. A. Fischer, and S. Walters, The seasonal cycle of atmospheric $\mathrm{CO}_{2}$ : A study based on the NCAR Community Climate Model (CCM2), J. Geophys. Res., 101, 15,079-15,097, 1996.
Fung, I., K. Prentice, E. Matthews, J. Lerner, and G. Russell, Threedimensional tracer model study of atmospheric $\mathrm{CO}_{2}$ : Response to seasonal exchanges with the terrestrial biosphere, J. Geophys. Res., 88, 1281-1294, 1983.

Fung, I. Y., C. J. Tucker, and K. C. Prentice, Application of advanced very high resolution radiometer vegetation index to study atmosphere-biosphere exchange of $\mathrm{CO}_{2}$, J. Geophys. Res., 92, 2999-3015, 1987.

Heimann, M., The global atmospheric tracer model TM2, Tech. Rep. 10, Dtsch. Klimarechenzentrum, Hamburg, Germany, 51 pp., 1995.

Heimann, M., and C. D. Keeling, A three-dimensional model of atmospheric $\mathrm{CO}_{2}$ transport based on observed winds, 2, Model description and simulated tracer experiments, in Aspects of Climate Variability in the Pacific and the Western Americas, Geophys. Monogr. Ser., vol. 55, edited by D. H. Peterson, pp. 237275, AGU, Washington, D.C., 1989.

Heimann, M., C. D. Keeling, and C. J. Tucker, A three-dimensional model of atmospheric $\mathrm{CO}_{2}$ transport based on observed winds, 3, Seasonal cycle and synoptic time scale variations, in Aspects of Climate Variability in the Pacific and the Western Americas, Geophys. Monogr. Ser., vol. 55, edited by D. H. Peterson, pp. 277-303, AGU, Washington, D.C., 1989.

Jacob, D. J., and M. J. Prather, Radon-222 as a test of convective transport in a general circulation model, Tellus, Ser. B, 42, 118134, 1990.

Jacob, D. J., M. J. Prather, S. C. Wofsy, and M. B. McElroy, Atmospheric distribution of ${ }^{85} \mathrm{Kr}$ simulated with a general circulation model, J. Geophys. Res., 92, 6614-6626, 1987.

Keeling, C. D., S. C. Piper, and M. Heimann, A three-dimensional model of atmospheric $\mathrm{CO}_{2}$ transport based on observed winds, 4, Mean annual gradients and interannual variations. Aspects of Climate Variability in the Pacific and the Western Americas, Geophys. Monogr. Ser., vol. 55, edited by D. H. Peterson, pp. 305-363, AGU, Washington, D.C., 1989.

Keeling, C. D., T. P. Whorf, M. Wahlen, and J. van der Plicht, Interannual extremes in the rate of rise of atmospheric carbon dioxide since 1980, Nature, 375, 666-670, 1995.

Law, R. M., Modelling the global transport of atmospheric constituents, Ph.D. thesis, Sch. of Earth Sci., Univ. of Melbourne, Parkville, Victoria, Australia, 1993.

Law, R., I. Simmonds, and W. F. Budd, Application of an atmospheric tracer model to the high southem latitudes, Tellus, Ser. $B, 44,358-370,1992$.

Mahlman, J. D., and W. J. Moxim, Tracer simulation using a global general circulation model: Results from a midlatitude instantaneous source experiment, J. Atmos. Sci., 35, 1340-1374, 1978.

Marland, G., Fossil fuels $\mathrm{CO}_{2}$ emissions: Three countries account for 50\% in 1988, in CDIAC Communications, Winter 1989, pp. 1-4, Carbon Dioxide Inf. Anal. Cent., Oak Ridge Natl. Lab., Oak Ridge, Tenn., 1989.

Nakazawa, T., K. Miyashita, S. Aoki, and M. Tanaka, Temporal and spatial variations of upper tropospheric and lower stratospheric carbon dioxide, Tellus, Ser. B, 43, 106-117, 1991.

Prather, M., M. McElroy, S. Wofsy, G. Russell, and D. Rind, Chemistry of the global troposphere: Fluorocarbons as tracers of air motion, J. Geophys. Res., 92, 6579-6613, 1987.

Prather, M., R. Derwent, D. Ehhalt, P. Fraser, E. Sanhueza, and $\mathrm{X}$. Zhou, Other trace gases and atmospheric chemistry, in Climate Change 1994: Radiative Forcing of Climate Change and An Evaluation of the IPCC IS92 Emission Scenarios, edited by J. Houghton et al., pp. 73-126, Cambridge Univ. Press, New York, 1995.

Ramonet, M., J. C. L. Roulley, P. Bousquet, and P. Monfray, Radon- 
222 measurements during the TROPOZ II mission, and comparison with a global atmospheric transport model, J. Atmos. Chem., 23, 107-136, 1996.

Rayner, P. J., and R. M. Law, A comparison of modelled responses to prescribed $\mathrm{CO}_{2}$ sources, Tech. Pap. 36, 82 pp., Div. of Atmos. Res., Commonw. Sci. Ind. Res. Organ., Aspendale, Victoria, Australia, 1995.

Russell, G. L., and J. A. Lemer, A new finite-differencing scheme for the tracer transport equation, J. Appl. Meteorol., 20, 14831498, 1981.

Schimel, D., I. Enting, M. Heimann, T. Wigley, D. Raynaud, D. Alves, and U. Siegenthaler, $\mathrm{CO}_{2}$ and the carbon cycle, in Climate Change 1994: Radiative Forcing of Climate Change and An Evaluation of the IPCC IS92 Emission Scenarios, edited by J. Houghton et al., pp. 35-71, Cambridge Univ. Press, New York, 1995.

Taguchi, S., Cross-tropical trajectories in the troposphere, J. Meteorol. Soc. Jpn., 72, 531-553, 1994.

Taguchi, S., A three-dimensional model of atmospheric $\mathrm{CO}_{2}$ transport based on analyzed winds: Model description and simulation results for TRANSCOM, J. Geophys. Res., 101, 15,099-15,109, 1996.

Tans, P. P., I. Y. Fung, and T. Takahashi, Observational constraints on the global atmospheric $\mathrm{CO}_{2}$ budget, Science, 247, 14311438, 1990.

Taylor, J. A., A stochastic Lagrangian atmospheric transport model to determine global $\mathrm{CO}_{2}$ sources and sinks - A preliminary discussion, Tellus, Ser. B, 41, 272-285, 1989.

Watterson, I. G., M. R. Dix, H. Gordon, and J. L. McGregor, The CSIRO 9-level atmospheric general circulation model and its equilibrium present and doubled $\mathrm{CO}_{2}$ climates, Aust. Meteorol. Mag., 44, 111-125, 1995.
A. S. Denning, Department of Atmospheric Science, Colorado State University, Fort Collins, CO 80523-1370. (e-mail: scott@abyss.atmos.colostate.edu)

D. Erickson, National Center for Atmospheric Research, P.O. Box 3000, Boulder, CO 80307. (e-mail: erickson@ucar.edu)

I. Y. Fung, Centre for Earth and Ocean Research, University of Victoria, British Columbia, Canada V8W 2Y2. (e-mail: inez@garryoak.seos.uvic.ca)

M. Heimann, Max Planck Institut für Meteorologie, Hamburg, Germany. (e-mail: heimann@dkrz.d400.de)

R. M. Law and P. J. Rayner, Cooperative Research Centre for Southern Hemisphere Meteorology, Monash University, Clayton, Victoria 3168, Australia. (e-mail: rml@vortex.shm.monash.edu.au; pjr@dar.csiro.au)

S. C. Piper, Scripps Institution of Oceanography, La Jolla, CA 92093-0220. (e-mail: scpiper@ucsd.edu)

M. Ramonet, Centre des Faibles Radioactivites, Laboratoire Mixte, CNRS/CEA, Gif-sur-Yvette Cedex, France. (e-mail: ramonet@asterix.saclay.cea.fr)

S. Taguchi, National Institute for Resources and Environment, Onogawa, Tsukuba, Ibaraki, Japan. (e-mail: p1871@nire.go.jp)

J. A. Taylor, Centre for Resource and Environmental Studies, Australian National University, Canberra, Australian Capital Territory, Australia. (e-mail: taylorj@cres.anu.edu.au)

C. M. Trudinger and I. G. Watterson, Division of Atmospheric Research, CSIRO, Aspendale, Victoria, Australia. (e-mail: cxt@dar.csiro.au; igw@dar.csiro.au)

(Received January 24, 1996; revised May 30, 1996; accepted June 5, 1996.) 